\title{
Characteristics of Burns Induced by Body Warming Devices
}

\author{
Hongsil Joo' ${ }^{1}$ Seungje Lee ${ }^{1}$, Kunyong Sung ${ }^{2 *}$ \\ ${ }^{1}$ Department of Plastic and Reconstructive Surgery, Hanil General Hospital, Seoul; '2Department of Plastic and Reconstructive Surgery, Kangwon National \\ University Hospital, Kangwon National University, College of Medicine, Chuncheon, Korea
}

\begin{abstract}
Background: As the use of handy warming devices such as hand warmers and electric heating pads has increased, the incidence of burns sustained from these devices has also increased. The aim of this study was to analyze the characteristics of burn cases induced by local body warming devices.

Methods: This retrospective study examined the records of 104 patients who had presented with burns sustained from warming devices between October 2015 and December 2017. The collected data was sorted according to type of warming device, gender, age, underlying diseases, affected body lesion, surgical operation rate, and treatment period. Results: The most commonly associated devices were hot packs (39.4\%). The predominant affected body lesion was the lower extremity (60.6\%). Patients were mainly female (67.3\%), and in their twenties. These victims generally visited our institution late after onset of their burns (mean 16.98 days) and had a high operation rate (86.5\%).

Conclusion: We recommend that the public should be better informed about the danger of sustaining burns while using handy body warming devices as a preventive strategy.
\end{abstract}

Keywords: Hot pack, Electrical heating pad, Burn

\section{서 론}

다양한 생활 편의 도구가 발달하면서 추위 속에서 활동할 때 몸의 일부분의 온도를 유지시켜 주거나, 추위에 노출되었던 신체의 일부 부위를 급속하게 체온을 상승시켜주는 핫팩이나 전기 방석과 같은 국소 온열 편의용품의 종류도 다양해지고 사용도 점차 증가하고 있다. 이러한 기 기들은 위험하다는 인식이 없어 부주의하게 사용되면서 국소 온열 편의용품에 화상을 입는 경 우가 늘어나고 있다. 핫팩 등과 같은 용품에 의한 화상은 용품이 닿는 부위 좁은 면적에만 화상 이 국한되고, 사용할 때 화상을 입을 만큼 뜨겁다고 인지하지 못하고 장시간 사용하는 경우가 많아 심재성 화상인 경우가 많았으며, 수상 후에도 대수롭지 않게 생각하고 치료를 받지 않아 치료시기를 놓치는 환자가 다른 종류의 화상을 수상한 경우보다 많았다. 이에 국소 온열 편의 용품으로 인한 화상환자의 특징을 분석하여 일반적인 화상환자와 다른 점을 비교해 보았다.

\section{방 법}

2015년 10월부터 2017년 12월까지 본원 성형외과에서 입원치료와 외래치료를 했던 환자 104명 을 대상으로 후향적으로 의무기록을 검토하였다. 대상은 휴대하여 체온을 유지해주는 온열 용 품이나 몸의 일부분에만 열을 전달하는 제품에 다친 환자들만으로 한정하였다. 화상을 유발 한 제품의 종류, 환자들의 성별과 나이, 기저질환, 화상부위 및 화상의 깊이, 치료방법의 종류 와수술 여부, 처음 화상을 수상한 날부터 치료를 받으러 올 때까지의 기간을 조사하였다.
Original Article

Received: February 28, 2018

Revised: April 9, 2018

Accepted: April 10, 2018

\section{Corresponding author:}

Kunyong Sung, M.D.

\section{Department of Plastic and Reconstructive Surgery, Kangwon National University Hospital, Kangwon National University College of Medicine, 156 Baengnyeong-ro, Chuncheon 24289, Korea \\ Tel: +82-33-258-9494 \\ Fax: +82-33-258-2000 \\ E-mail: ps@kangwon.ac.kr}

This is an Open Access article distributed under the terms of the Creative Commons Attribution Non-Commercial License (http://creativecommons.org/licenses/by-nc/4.0/) which permits unrestricted non-commercial use, distribution, and reproduction in any medium, provided the original work is properly cited.

(c) 2018 Korean Wound Management Society 


\section{결 과}

2015년 10월부터 2017년 12월까지 외래 및 입원을 통해 치료받은 환자 는 모두 104 명이었으며 그 중 남자는 34 명, 여자는 70 명으로 여성이 사 고를 당하는 비율이 높았다. 연령은 9 세부터 89 세까지 모든 나이에서 화상을 입은 경험이 있었다. 그 중 20-39세가 34 명(32.7\%)으로 가장 많 았으며 이어 40-59세가 27명(25.9\%)이었고 전체 연령 중 20대가 20명 으로 가장 많은 비율을 차지했다. 104 명의 환자 중 50 명은 기저질환이 없었고 기전질환이 있는 환자에서는 당뇨, 고혈압, 뇌졸증, 치매 등을 한 가지나 한 가지 이상 않고 있었다(Table 1).

화상을 수상한 신체부위는 하지가 63 명 $(60.6 \%)$ 으로 가장 많았으 며 이어 발이 17 명으로 두 번째로 많았고, 그 다음은 엉덩이 등의 순 서였다(Table 2). 화상을 유발한 제품으로는 핫팩이 41 건으로 가장 많 았고 전기 방석이나 매트가 29 건, 찜질팩이 10 건이었으며 족욕기나 물 주머니에 수상한 경우도 있었다. 화상의 깊이와 제품의 종류 간의 연 관성은 없었다(Table 3).

Table 1. Patient dermographics

\begin{tabular}{lc}
\hline Characteristics & Unit \\
\hline Sex & $70(67.3 \%)$ \\
Female & $34(32.7 \%)$ \\
Male & \\
Age & $13(12.5 \%)$ \\
$<20$ & $34(32.7 \%)$ \\
$20-39$ & $27(25.9 \%)$ \\
$40-59$ & $24(23.1 \%)$ \\
$60-79$ & $6(5.8 \%)$ \\
$\geq 80$ & \\
Underlying disease & 20 \\
DM & 18 \\
HTN & 2 \\
Parkinson & 4 \\
Cancer & 3 \\
Stroke & 1 \\
Dementia & 6 \\
Other & 50 \\
None & \\
\hline
\end{tabular}

Table 2. Region of burns

\begin{tabular}{lc}
\hline Region & No. of patients \\
\hline Lower extremity & $63(60.6 \%)$ \\
Foot & $17(16.3 \%)$ \\
Upper extremity & $10(9.6 \%)$ \\
Buttock & $12(11.5 \%)$ \\
Head \& Neck & $2(1.9 \%)$ \\
\hline
\end{tabular}

대부분의 환자에서 화상의 깊이가 심재성인 깊은 2 도와 3 도 화상 이었다. 3 도 화상이 83 명 $(79.8 \%), 2$ 도 화상환자 중에서도 깊은 2 도 화 상이 10 명, 얕은 2 도 화상은 9 명, 1 도 화상은 2 명이었다. 상처의 크기 는 평균적으로 $13.93 \mathrm{~cm}^{2}$ 이었으며 범위는 $0.5 \mathrm{~cm}^{2}$ 에서 $168 \mathrm{~cm}^{2}$ 이었다. 화상 수상 부위에 2 가지 이상의 화상의 깊이가 혼재되어 있을 경우 면적이 넓은 쪽 화상의 깊이를 통계에 포함하였다(Table 4).

화상을 입은 후 치료받으러 올 때까지의 기간은 16.98 일로 치료시 기가 늦었으며 수상 후 99 일 후에 치료를 받으러 오기도 하였다. 치료 받으러 올 때까지의 기간은 이전의 화상 전문 기관이 아닌 곳에서 치 료하였거나 자가 치료한 기간을 포함하였으며 본원을 방문하기 전까 지 전혀 치료를 하지 않은 경우도 있었다. 내원 시기를 기간별로 보면 수상 후 1 주에서 2 주 사이에 전문기관을 방문하는 경우가 36 명으로 제일 많았으며 그 중에서도 14 일째 오는 환자가 12 명이었다. 치료를 받으러 올 때까지 기간의 3 주 이상일 경우는 화상의 깊이가 모두 3 도 화상이었다(Table 5). 치료를 받은 환자 중 13 명의 환자는 일반적인 치 료로 회복되었으나 91 명 $(87.5 \%)$ 의 환자는 수술을 시행하였다. 시행받 은 수술로는 부분층 식피술이 38 명, 전층 피부이식술이 9 명, 전진이 나 회전, 천공지 피판을 포함한 국소 피판술이 42 명, 대둔근을 이용한 피판술이 1 건이 있었으며 환자가 고령으로 인해 변연절제술 후 Allo$\operatorname{derm}^{\circledR}$ 을 적용한 뒤 일반적인 치료로 이차적 상처 구축을 유도하고 있는 환자가 1 명 있었다(Table 6).

Table 3. Type of cause

\begin{tabular}{|c|c|c|c|c|c|}
\hline \multirow[b]{2}{*}{ Cause } & \multirow[b]{2}{*}{ №. of patients } & \multicolumn{4}{|c|}{ Severity (degree) } \\
\hline & & First & $\begin{array}{l}\text { Sup. } \\
\text { second }\end{array}$ & $\begin{array}{c}\text { Deep } \\
\text { second }\end{array}$ & Third \\
\hline Hot pack & 41 (39.4\%) & 1 & 1 & 2 & 37 \\
\hline Electric pad & 29 (27.9\%) & & 2 & 2 & 25 \\
\hline Polymeric gel pack & $10(9.6 \%)$ & & 2 & 2 & 6 \\
\hline Electric water pad & 7 (6.7\%) & & 1 & 3 & 3 \\
\hline Foot baths & $3(2.9 \%)$ & & 2 & 1 & \\
\hline Water bottle & $2(1.9 \%)$ & 1 & 1 & & \\
\hline Other & $12(11.5 \%)$ & & & & 12 \\
\hline
\end{tabular}

Table 4. Wound charateristics

\begin{tabular}{lc}
\hline Characterics & Unit \\
\hline Burn depth & No. of patients \\
First degree & $2(1.9 \%)$ \\
Second degree & \\
Superficial & $9(8.7 \%)$ \\
Deep & $10(9.6 \%)$ \\
Third degree & $83(79.8 \%)$ \\
Wound size & \\
Range & $0.5-168 \mathrm{~cm}^{2}$ \\
Mean & $13.93 \mathrm{~cm}^{2}$ \\
\hline
\end{tabular}


Joo $\mathrm{H}$ et al.

Burns by body warming devices

Table 5. Relationship between time and injury

\begin{tabular}{|c|c|c|c|c|c|}
\hline \multirow{2}{*}{$\begin{array}{l}\text { Time from burn onset } \\
\text { to clinical visit }\end{array}$} & \multirow[b]{2}{*}{ №.of patient } & \multicolumn{4}{|c|}{ Severity (degree) } \\
\hline & & First & $\begin{array}{l}\text { Sup. } \\
\text { second }\end{array}$ & $\begin{array}{l}\text { Deep } \\
\text { second }\end{array}$ & Third \\
\hline $0-7$ days & 26 & 2 & 6 & 2 & 16 \\
\hline 8-14 days & 36 & & 3 & 5 & 28 \\
\hline $15-21$ days & 21 & & & 3 & 18 \\
\hline $22-28$ days & 6 & & & & 6 \\
\hline 29-99 days & 15 & & & & 15 \\
\hline Range & 0-99 days & & & & \\
\hline Mean & 16.98 days & & & & \\
\hline
\end{tabular}

\section{증례 1}

9세 여아로 스키캠프에서 양말 안에 핫팩을 넣고 하루 수업을 받은

Table 6. Treatment

\begin{tabular}{lc}
\hline Conservative treatment & $13(12.5 \%)$ \\
Operative treatment & $91(87.5 \%)$ \\
STSG & 38 \\
FSG & 9 \\
Local flap & 42 \\
Muscle flap & 1 \\
Alloderm ${ }^{\circledR}$ apply & 1 \\
\hline
\end{tabular}
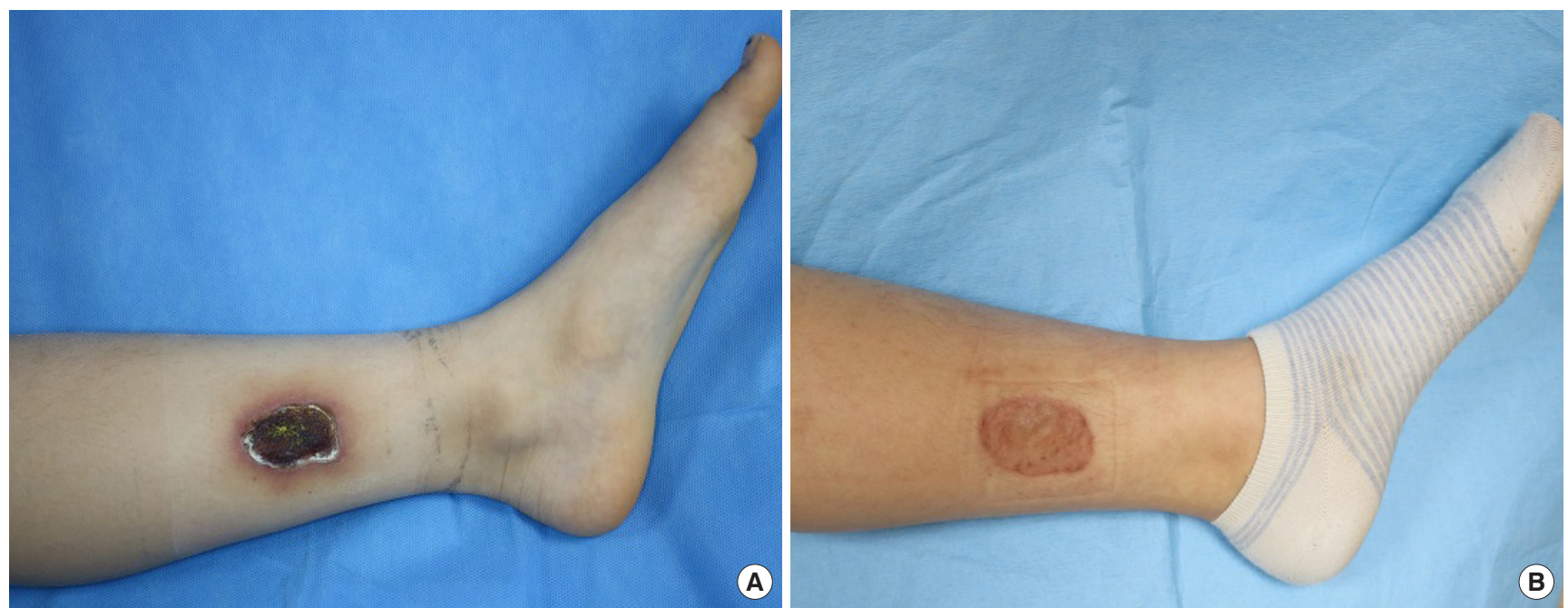

Fig. 1. (A) Preoperative image: $3 \mathrm{~cm} \times 5 \mathrm{~cm}$ sized black eschar \& marginal erythema on Rt. Medial ankle. (B) Postoperative image: STSG state.
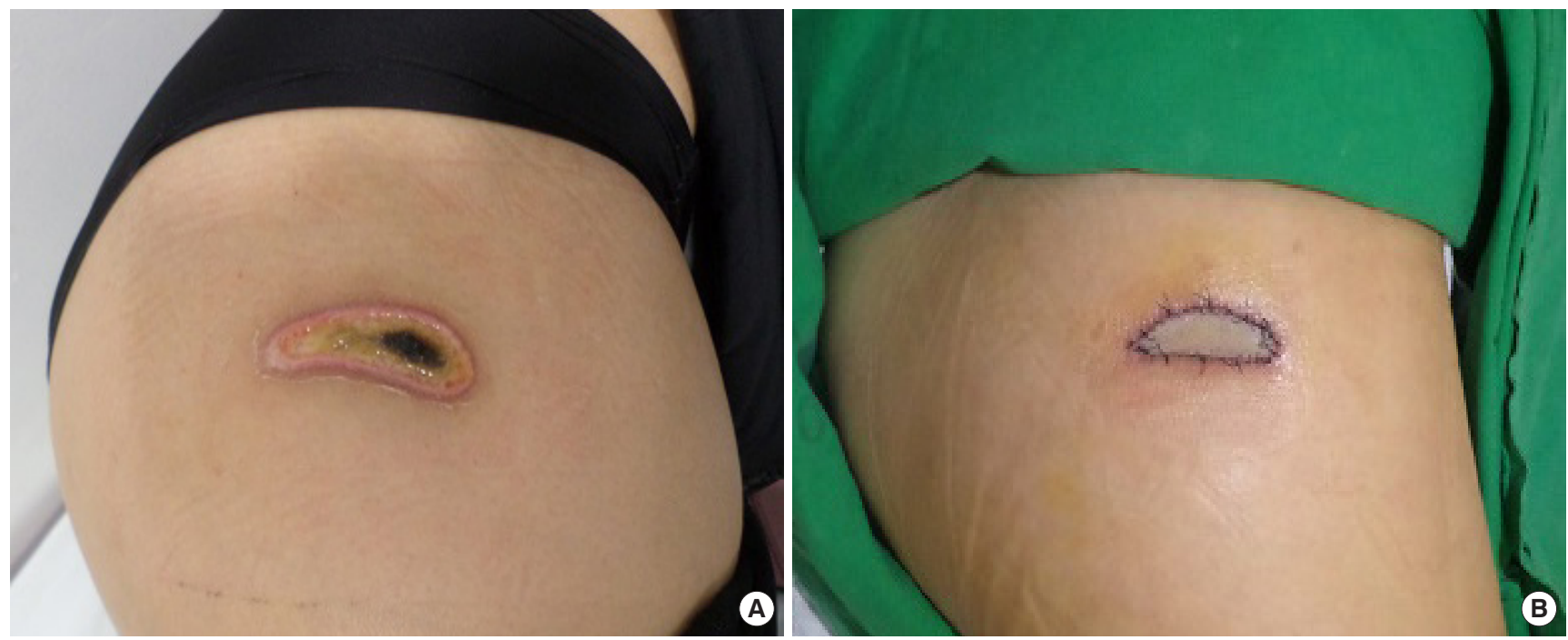

Fig. 2. (A) Preoperative image: $1.5 \mathrm{~cm} \times 6 \mathrm{~cm}$ sized yellowish eschar \& dermal layer exposure on Rt. Lateral thigh. (B) Postoperative image: FTSG state. 
뒤 약간의 통증과 삼출물이 생겼으나 집에서 자가 치료하다 1 주일째 내원하였다. 오른쪽 발목에 $3 \mathrm{~cm} \times 5 \mathrm{~cm}$ 크기의 가피가 형성된 3 도 화 상이었고 부분층피부이식술을 시행하였다(Fig. 1).

\section{증례 2}

29세 여자 환자로 전기장판에서 자고 난 뒤 수상한 분으로 초기에는 피부색 변화만 있고 삼출물이나 통증이 없어 치료하지 않고 지내다 수상 후 21 일째 내원하였다. 오른쪽 대퇴부 옆면에 $1.5 \mathrm{~cm} \times 6 \mathrm{~cm}$ 크기 의 3 도 화상으로 전층피부이식술을 시행하였다(Fig. 2).

\section{고 찰}

핫팩과 같은 용품들은 추위에 노출된 몸의 일부분만을 체온을 유지 해주거나체온을 빠르게상승시켜 줄수 있어 외부 활동을 하는 경우 나 외출 후 보온을 위해 간편하게 사용되고 있다. 추위로부터 체온을 보존해주는 핫팩, 찜질팩, 전기방석 등과 같은 국소 온열 편의용품들 은 편리성과 활동 인구의 증가로 수요가 늘어나면서 다양하게 개발 되고 사용도 늘면서 이런 편의용품의 부주의한 사용으로 인한 화상 도 증가하고 있다.

환자는 주로 여성이었으며 이는 국민건강보험을 자료로 한 전체 화 상의 역학 조사와 같은 결과였으며 전기장판만을 대상으로 한 연구 에서도 여성 환자가 많았다[1-3]. 연령별 특징을 보면 모든 연령에서 화상이 발생하였으나 특히 20-39세에서 가장 많이 발생하였다. 이는 전체 화상을 대상으로 한 연구에서의 호발 연령 20-49세와 비슷한 분포를 보였다. 20,30 대가 많은 것은 외부 활동이 가장 활발한 나이이 고 핫팩이나 충전식 온열 편의 용품 등을 쉽게 접하고 쓰는 데 익숙하 기 때문인 것으로 생각된다 [1,2]. 60대 이상의 노령층에서도 적지 않은 환자가 발생하였는데 외부 활동은 적지만 기저질환이 있는 경우가 많 고족욕이나온 찜질 등을 선호하는 연령이라 그런 것으로 생각된다.

가장 많이 화상을 수상한 부위는 하지, 발, 엉덩이 순이었다. 환자 들이 주로 바지나 두꺼운 외투 주머니 속에 온열 용품을 넣고 장시간 있었다고 진술한 경우가 많았으며 신발이나 양말 안에 핫팩이나 온열 기를 넣고 운동이나 일을 한 경우도 다수 있어 하지 중에서도 대퇴부 앞면이나 옆면이 손상을 받았고 발과 엉덩이 부위에 화상을 많았던 것으로 생각된다. 전기 장판에 의한 접촉화상의 보고에서는 호발 부 위가 하퇴부와 엉덩이로 저자들과 비슷한 결과를 보였으나 국민건강 보험 자료에 의한 전체 화상을 대상으로 한 연구에서는 호발 부위가 상지와 손으로 저자들의 조사와 다른 결과를 보였다. 이는 손과 상지 가 신체에서 가장 활동이 많은 부위로 뜨거운 물건이나 불을 직접 만 지거나 옮기다가 사고를 당하는 경우가 많아서 호발 부위가 된 것으 로 생각된다[1-3].

국소 온열 편의용품에 의한 화상의 깊이는 깊은 2 도나 3 도 화상이 104 명의 환자 중 93 명으로 심각한 상처를 입은 경우가 대다수였으며 수술의 비율도 $87.5 \%$ 로 높았다.

국소 온열 편의용품은 짧은 시간 안에 화상을 입지 않을 정도의 체 온과 비슷한 정도의 온도라 사용하면서 뜨거움을 잘 느끼지 못해 장
시간 사용하게 되고 같은 부위에 계속 접촉되어 있어 시간이 경과함 에 따라 온도가 상승하고 손상이 누적되어 화상을 입게 한다. 미국 화상 학회지와 Moritz 등의 연구에 의하면 $44^{\circ} \mathrm{C}$ 에서도 6 시간, $45^{\circ} \mathrm{C}$ 에 서는 3 시간, $48^{\circ} \mathrm{C}$ 는 15 분만 노출되어도 심각한 화상을 입을 수 있다 고 하였다[4,5]. 전류가 통하는 온열기의 경우 온도 조절 장치가 있더 라도 설정된 온도에 다다른 후에도 시간이 지나면 지속적으로 완만 하게 온도가 상승한다는 보고가 있어 전기 방석이나 온수 매트 같은 용품은 장시간 사용할 때 깊은 화상을 입을 수 있는 요인이 되었을 것 으로 생각된다[6].

또한 손상받은 크기가 작고 초기에는 통증이 별로 없기 때문에 대 수롭지 않게 생각하여 치료하지 않거나 전문기관에서 치료하지 않아 깊은 화상으로 전환되는 경우도 있어 수술 비율이 높은 것으로 생각 된다. 화상은 수상 후 첫 48시간 안에 적절한 치료가 없을 경우 더 깊 은 범위로 진행될 수 있고 화상을 수상 후 전문 기관을 빠른 시일 내 에 방문하여 치료받은 환자 군이 늦게 방문하여 치료한 환자 군보다 치료시기가 더 짧았다는 보고가 있다[7,8]. 이번 조사에서 환자들이 전문의료기관 방문까지의 시간은 16.98 일로 초기 치료시기를 놓쳐 수술을 필요로 하는 깊은 화상으로 전환된 경우도 다수 있어 수술의 비율이 높은 것으로 생각된다. 2 주가 지난 후 방문한 환자들은 모두 깊은 2 도이거나 3 도 화상이었으며 3 주 이상 지난 후 치료를 받으러 온 환자들은 모두 3 도였다.

수술적 치료로는 국소 피판술이 제일 많이 시행해졌고 그 다음으 론 부분층 식피술, 전층 식피술 순이었다. 상처 부위의 크기가 평균적 으로 $13.93 \mathrm{~cm}^{2}$ 로 용품이 닿는 부분으로 국한된 작은 크기인 경우가 많아 비교적 간단한 술기로 치료가 되었다.

핫팩과 같은 국소 온열 편의품으로 인한 화상은 화상의 범위가 작 은 범위로 국한된 경우가 많으나 장시간 사용으로 깊은 화상인 경우 가 많고, 수상 후부터 치료 때까지 기간이 길어 치료시기를 놓쳐 악화 되는 일도 많아수술의 비율이 높은 특징이 있다. 부주의한 사용으로 심각한 화상을 입을 수 있음에도 사용시 주의 사항이나 위험성이 알 려지지 않아 피해가 늘고 있어 온열 용품 사용 시 위험성을 조금 더 강화하여 알려야할 것으로 생각된다.

\section{References}

1. Oh HJ, Boo SJ. Burns in South Korea: an analysis of nationwide data from the health insurance review and assessment service. Burns 2016;42:675-81.

2. Kim DC, Lee R, Kim JH, et al. Epidemiology of burns in Korea from 2010 to 2014. J Korean Burn Soc 2015;18:1-6.

3. Kwon DH, Ko JH, Hur GY, et al. Contact burn caused by electrical pad. J Korean Burn Soc 2012;15:9-14.

4. Moritz AR, Herriques FC. Studies of thermal injury II. The relative importance of time and surface temperature in the causation of cutaneous burns. AM J Path 1947;23:695-720.

5. American Burn Association. Scald injury prevention: educa- 
Joo $\mathrm{H}$ et al.

Burns by body warming devices

tor's guide 2008, p. 3.

6. Kim SS, Yang WS, Sim JH, et al. The mechanism of low temperature burn and clinical cases. J Korean Burn Soc 2015; 18:74-80.

7. Papp A, Kiraly K, Harma M, et al. The progression of burn depth in experimental burns: a histological and methodological study. Burns 2004;30:684-90.

8. Choi MS, Lee HJ, Lee JH. Early intervention for low-temperature burns: comparison between early and late hospital visit patients. Arch Plast Surg 2005;42:173-8. 